\title{
EXPERIMENTOS NO ENSINO DE FÍSICA: um olhar de viés epistemológico
}

\author{
Sérgio Choiti Yamazakil \\ Regiani Magalhães de Oliveira Yamazaki2
}

\section{RESUMO}

Neste trabalho apresentamos uma pesquisa empírica com alunos de um curso de licenciatura em Física de uma universidade pública do Estado de Mato Grosso do Sul. A investigação teve como objetivo identificar concepções dos alunos de uma turma de primeiro ano do curso com relação ao uso de experimentos e de suas relações com o ensino e aprendizagem de Física, sob um olhar epistemológico. Essa pesquisa foi motivada pela necessidade de uma discussão sobre os aspectos que permeiam o laboratório didático, tendo em vista a congruência entre as concepções espontâneas de estudantes encontradas na literatura da área e as opiniões dos alunos iniciantes no curso de Física, há alguns anos. A análise foi fundamentada na analogia feita por Fernando Becker, que diz respeito às relações existentes entre as concepções sobre o fazer ciência e aquelas relacionadas ao ensino aprendizagem, e na epistemologia crítica de Gaston Bachelard. Os resultados apontam para a presença de concepções epistemológicas ambíguas entre os estudantes, o que remete à necessidade de reformulação no que tange aos cursos de formação de professores de Física. Em seguida discutimos a formação inicial de professores segundo pesquisadores do campo do ensino de ciências, epistemólogos e sociólogos da ciência. Por fim, algumas sugestões são feitas para os cursos de licenciaturas em Física, com o objetivo de minimizar a formação ou manutenção do senso comum sobre essa ciência e seu ensino aprendizagem.

Palavras-chave: Experimentos no ensino de física. Epistemologia. Concepções espontâneas. Didática da Ciência.

\footnotetext{
1 Doutor em Educação Científica e Tecnológica pela Universidade Federal de Santa Catarina (UFSC), Mestre em Ensino de Ciências pela Universidade de São Paulo (USP). Docente e Orientador no Mestrado em Educação Científica e Matemática da Universidade Estadual de MS. Grupo de Pesquisa em Ensino de Ciências de MS. E-mail: sergioyamazaki@gmail.com

2 Doutora em Educação Científica e Tecnológica pela Universidade Federal de Santa Catarina (UFSC), Mestre em Ensino de Ciências pela Universidade Federal de Mato Grosso do Sul (UFMS). Docente na Universidade Federal da Grande Dourados (UFGD) e na Universidade Estadual de MS (UEMS). Grupo de Pesquisa em Ensino de Ciências de MS. Grupo de Pesquisa - Núcleo de Estudos em Ensino de Genética, Biologia e Ciências - NUEGUFSC E-mail: regianibio@gmail.com
} 


\title{
EXPERIMENTS IN PHYSICS TEACHING: an epistemological analysis
}

\begin{abstract}
In this paper we present an empirical research with students of a initial training course of physics teachers of a public university of the State of Mato Grosso do Sul. The objective of the investigation was to identify the conceptions of the students of a class of first year of the course with respect to the use of experiments and its relations with the teaching and learning of Physics, from an epistemological perspective. This research was motivated by the need for a discussion about the aspects that permeate the didactic laboratory, in view of the similarity between the spontaneous conceptions of students found in the literature of the area and the opinions of the students beginning in the Physics course, some years ago. The analysis was based on the analogy made by Fernando Becker, which concerns the relations between the conceptions about doing science and those related to teaching learning, and on the critical epistemology of Gaston Bachelard. The results point to the presence of ambiguous epistemological conceptions among the students, which refers to the need for reformulation regarding the training courses of physics teachers. In the sequence, we discussed the initial formation of teachers according to researchers in the field of science education, epistemologists and sociologists of science. Finally, some suggestions are made for undergraduate courses in Physics, with the aim of minimizing the formation or permanence of common sense about this science and its teaching learning.
\end{abstract}

Keywords: Experiments in Physics teaching. Epistemology. Spontaneous Conceptions. Didactics of Science.

\section{EXPERIENCIAS EN ENSEÑANZA DE LA FíSICA: un análisis epistemológico}

\section{RESUMEN}

En este artículo se presenta una investigación empírica con los estudiantes de un curso de licenciatura en física en una universidad pública del estado de Mato Grosso do Sul. La investigación tuvo como objetivo identificar las concepciones de los estudiantes en una clase de primer año, con respecto al uso de experimentos y su relación con la enseñanza y el aprendizaje de la física, bajo una mirada epistemológica. Esta investigación fue motivada por la necesidad de una discusión de los aspectos que se relacionan con el laboratorio de enseñanza, debido a la congruencia entre las concepciones espontáneas de los estudiantes que se encuentran en la literatura y las opiniones de los estudiantes que comienzan en curso de física, desde hace algunos años. El análisis tomó como base la analogía hecha por Fernando Becker, con respecto a las relaciones entre las concepciones de hacer ciencia, y los relacionados con la enseñanza y el aprendizaje, y la epistemología crítica de Gaston Bachelard. Los resultados indican la presencia de conceptos epistemológicos ambiguas entre los estudiantes, lo que conduce a la necesidad de reformulación de los cursos de formación para profesores de física. En la secuencia, discutimos la formación inicial de profesores según investigadores del 
campo de la enseñanza de ciencias, epistemológos y sociólogos de la ciencia. Por último, se hacen algunas propuestas para los cursos de licenciatura en física, con el fin de minimizar la formación o el mantenimiento del sentido común en esta ciencia y su enseñanza aprendizaje.

Palabras clave: Experiências en Enseñanza de la Física. Epistemología. Concepciones Espontâneas. Didáctica de la Ciencia.

\section{INTRODUÇÃO}

Os problemas inerentes ao ensino de Física não são novos, e a literatura tem apontado que uma das dificuldades parece estar relacionada ao emprego de métodos didático-pedagógicos embasados em concepções tradicionais de ensino e aprendizagem.

Nos últimos 20 anos, muitos trabalhos foram apresentados nas revistas e congressos de Ensino de Ciências, sugerindo formas de ensinar que levam em consideração pressupostos que se distanciam do ensino conhecido como tradicional. As sugestões têm em comum a transformação do aluno passivo e tabula rasa, em um estudante ativo, reflexivo, questionador e criativo, que conhece algo sobre os temas escolares a serem abordados, as concepções prévias que foram amplamente debatidas a partir das últimas décadas do século passado.

No entanto, apesar das intensas tentativas visando uma aprendizagem mais eficaz, significativa, que condiz com a literatura da área, uma hipótese que a nosso ver deve ser investigada seria a de que o estudante traz em sua bagagem escolar e cotidiana uma formação epistemológica que busca sustentar pressupostos que se aproximam de uma educação tradicional, o que implicaria em um redimensionamento didático-pedagógico caracterizado por estudos e discussões dentro do campo da epistemologia.

Nesse cenário, essa pesquisa procura analisar o que alunos do primeiro ano de um curso de Física, de uma Universidade Pública de Mato Grosso do Sul, pensam a respeito de uma das atividades que, para muitos profissionais, é considerada um dos principais caminhos didáticos para se ensinar Física: as atividades experimentais. Há centenas de artigos na literatura que 
defendem essa atividade como uma solução para motivação e aprendizagem dessa ciência, o que justifica investigá-la com um pouco mais de profundidade.

\section{SOBRE USO DE EXPERIMENTOS COMO ATIVIDADE DIDÁTICA}

O uso de experimentos para o ensino de ciências tem sido há bastante tempo sugerido como alternativa significativa para uma mudança nos métodos de ensino que são baseados em uma perspectiva tradicional (BONADIMAN, NONENMACHER, 2007).

Segundo Moraes e Silva Junior (2014), a produção científica indica um aumento no número de propostas de experimentos didáticos nos últimos anos, o que justificam pesquisas sobre as especificidades destas práticas para o ensino de ciências. Entre as possibilidades didáticas, Giordan (1999) cita o desenvolvimento da motivação para o estudo das ciências, de discussões sócio-técnico-cognitivas, além daquelas relacionadas a questões de ordem histórica, sociológica e epistemológica. Somam-se a este conjunto de fatores por trás das atividades experimentais, uma compreensão das relações presentes entre conhecimento e realidade que se sobressaem perante um método científico empregado, o que pode levar a certas compreensões epistemológicas (HIGA, OLIVEIRA, 2012).

Contudo, apesar do uso de experimentos mostrar-se potencialmente útil, do ponto de vista didático, algumas pesquisas mostraram que distintas estratégias de ensino indicam resultados discordantes no que se refere à aprendizagem (PINHO ALVES, 2000). Nesse sentido, Barbosa, Paulo e Rinaldi (1999) apresentam resultados de uma pesquisa segundo os quais o emprego de uma abordagem construtivista em um ensino com uso de experiências é mais eficiente, permitindo uma aprendizagem mais significativa.

No entanto, ao conceber a atividade experimental como instrumento de ensino algumas dificuldades podem obstaculizar seu emprego. Uma pesquisa de Pena e Ribeiro Filho (2009) mostra que professores e 
pesquisadores apontam, além das condições de trabalho, a falta de formação docente como obstáculo para utilização do laboratório didático.

Essas questões, que problematizam o efetivo exercício de experimentações para o ensino de ciências, também são nossas, uma vez que nesse trabalho analisamos concepções de futuros professores de Física trazidas do meio escolar e cotidiano. No caso desta investigação, nosso recorte envolve as questões relacionadas às concepções epistemológicas presentes nas respostas dos alunos, e de suas interconexões com fatores didático-pedagógicos. Este enfoque, adotado para análise dos dados desta pesquisa, é fundamentado em trabalhos de Fernando Becker, particularmente em suas obras que dizem respeito à Epistemologia do Professor, e em noções da epistemologia de Gaston Bachelard.

\section{SOBRE AS REFERÊNCIAS TEÓRICAS ADOTADAS: a epistemologia do professor}

As pesquisas de Becker $(2012 ; 2009 ; 1993)$ apresentam concepções do professor, dos níveis básicos ao universitário, incluindo pesquisadores que trabalham nas pós-graduações (BECKER, 2009) com relação a alguns aspectos ligados à matemática e ao seu ensino e aprendizagem, que podem ser estendidos ao ensino de ciências (BECKER, 2012).

Becker (2009) mostra que o professor pensa o conhecimento científico através do senso comum, como um indivíduo que "só usa sua inteligência para resolver os problemas do cotidiano" (p.89). Para o professor, "o conhecimento é algo que entra pelos sentidos - algo que vem de fora da pessoa, portanto - e se instala no indivíduo, independentemente de sua vontade" (p.89). Essa forma de pensar a constituição do conhecimento pelos sujeitos carrega a noção de um sujeito passivo, que não tem um papel sobre sua própria construção, o que remete à gênese do conhecimento, em uma compreensão epistemológica empirista.

"Podemos dizer que empiristas são aqueles que pensam que 0 conhecimento acontece porque nós vemos, ouvimos, tateamos etc., e não porque agimos" (BECKER, 2009, p.90), o que significa que o conhecimento é 
"sensivel no começo e abstrato depois" (BECKER, 2009, p.90). Esta percepção do processo de elaboração do saber empirista é a que é compreendida pela teoria da associação entre estímulo e resposta, amplamente considerada pelo método de ensino tradicional desde algumas décadas.

No entanto, as pesquisas de Becker (2012; 2009; 1993) mostram que quando a concepção empirista do professor é problematizada, ele inconscientemente volta-se contra suas próprias concepções, fornecendo respostas racionalistas ou aprioristas.

O apriorismo, como gênese do conhecimento, pode ser enquadrado junto ao racionalismo (HESSEN, 2000), pois é uma categoria segundo a qual o conhecimento é elaborado em primeira instância pelo sujeito, seja esta influência baseada em elementos inatos (aprioristas) ou socialmente construídos, ao contrário do empirismo, que tem no objeto a influência primeira na elaboração do conhecimento.

Para Becker (2012; 2009), somente a reflexão sobre suas próprias práticas pode fazer com que o professor mude suas ações didáticas e seus pensamentos. E esta autoanálise pode ter caminhos diversos, tais como a consideração de distintas referências teóricas. O autor, ao chamar atenção para este ponto, afirma que irá se fundamentar na epistemologia de Jean Piaget, mas cita a epistemologia de Bachelard como potencial interpretativo e crítico (BECKER, 2012). Nossa interpretação será feita, portanto, à luz dessa epistemologia, não somente em função dessa sugestão, mas porque ela faz uma extensa discussão sobre as relações entre sujeito e objeto, nas ciências e na atividade docente, permitindo analisá-las do ponto de vista didático-pedagógico.

Para Bachelard (1996; 1971), o ensino de ciências deve seguir a história, ou seja, deve ser planejado de acordo com os fatos e discussões que são encontrados na evolução de suas ideias. Além disso, na origem do conhecimento, o ensino deve problematizar tanto objeto como sujeito, apontando para uma relação dialética, em que a construção do 
conhecimento acontece pela interação entre essas instâncias aparentemente dicotômicas, no que tange a suas funções.

Nesse sentido, não é nem no sujeito, nem no objeto, mas em suas relações que o conhecimento é gerado, o que nos leva às pontuais reflexões de Becker (2012; 2009; 1993). Ao conceber o ensino transmissivista (um dos aspectos do ensino tradicional), concebe-se ao mesmo tempo que o objeto (natureza, ou realidade) está fora do sujeito, o que justificaria a transmissão de um saber. "Basta que o aluno preste muita atenção ao objeto, porque é dele que o conhecimento é gerado". É imprescindível que se perceba o papel passivo do aluno para aprendizagem deste saber, restando-lhe apenas o papel de memorização, repetição e extensão do saber para casos semelhantes.

Ao contrário, tanto Becker (1993) quanto Bachelard nos mostra que a construção do conhecimento vem de elementos relacionados ao sujeito (de suas concepções sobre os objetos em questão) e das especificidades dos objetos, em uma interação de fatores. Esses autores mostram que há um vaivém entre conotações empíricas e racionalistas, e que nenhuma delas se sustenta sozinha quanto à gênese do conhecimento. Esse aspecto da origem do conhecimento tem como perspectiva um olhar dual para o fazer científico, ou, para o fazer do pesquisador, o que significa que tanto o objeto quanto o sujeito estão sempre presentes na elaboração de um saber. Portanto, seria um equívoco pensar na existência de momentos em que experiências ou teorias ditam as regras de forma uníssona: sujeito sem objeto ou objeto sem sujeito.

Para resolver esse equívoco didático e epistemológico, ambos os autores sugerem a reflexão crítica, atitude que Bachelard denomina de catarse intelectual e afetiva, pois essa compreensão - assim como os elementos nela implícitos - está enraizada como resultado de uma história que insiste em perpetuá-la.

Para Bachelard (1996), essa catarse envolve os aspectos que se referem às concepções sobre $\mathrm{o}$ ensinar e $\mathrm{o}$ aprender e sobre as próprias 
ciências, o que torna bastante complexa suas relações, dificultando uma plena formação docente. Para esse filósofo, são obstáculos que devem ser superados para que as ciências e seu exercício sejam globalmente compreendidos.

Uma questão, portanto, que procuramos refletir é: de que forma podemos enfrentar esse desafio?

\section{METODOLOGIA DA PESQUISA}

Nessa pesquisa buscamos analisar dados de um questionário que se utilizou da escala do tipo Likert (LIKERT, 1932), um instrumento para medida de atitudes que corresponde ao grau de concordância a uma série de afirmações sobre determinado tema ou objeto a ser pesquisado, às quais deve-se dar uma resposta que varia conforme segue: 5 pontos - totalmente de acordo; 4 pontos - de acordo; 3 pontos - neutro; 2 pontos - em desacordo; 1 ponto - totalmente em desacordo.

Para análise dos resultados, foi utilizado um Ranking Médio (RM) dos pontos fornecidos a cada questão, dado pela equação: $R M=\sum\left(f_{i} V_{i}\right) /\left(N_{A}\right)$, onde $f_{i}$ é a frequência de cada resposta à questão, $V_{i}$ é o valor do item supracitado (de 1 a 5 pontos) e $N_{A}$ é o número de alunos que responderam à questão.

O indicativo do nível de concordância foi fornecido pelo seguinte critério: $R M \leq 1,4$ (totalmente em desacordo); 1,5 $\leq \mathrm{RM} \leq 2,4$ (em desacordo); $2,5 \leq R M \leq 3,4$ (neutro); $3,5 \leq R M \leq 4,4$ (de acordo); 4,5 $\leq R M \leq 5,0$ (totalmente de acordo). Esse critério se justifica na medida em que os pontos de 1 a 5 consideram o nível crescente de concordância, dada pelo valor de $\mathrm{V}_{\mathrm{i}}$ na equação de RM.

O questionário foi aplicado a uma turma de 39 alunos de um curso de licenciatura em Física, de uma Universidade Pública do Estado de Mato Grosso do Sul.

O questionário procurou levantar concepções dos alunos sobre as atividades experimentais e sobre o que pensavam sobre física e seu ensino. 
As questões foram elaboradas levando em consideração os resultados das pesquisas de Becker $(2012,1993)$, para verificação ou não das contradições epistemológicas e didático-pedagógicas por ele verificadas; são as que seguem: Questão 1: Escolas com bons laboratórios têm um ensino de melhor qualidade; Questão 2: Físicos observam a natureza e, a partir de sua observação elaboram as teorias; Questão 3: Experimentos comprovam teorias; Questão 4: O professor deve transmitir o conhecimento e o aluno deve aceitá-lo passivamente.

Uma semana após a aplicação do questionário, para iniciar as discussões sobre as respostas fornecidas, as questões de 1 a 4 foram postas na forma oral pelo professor para que os alunos se manifestassem a respeito do que pensam, a fim de verificar se suas respostas não foram aleatórias, impensadas, pois as mesmas requeriam apenas a marcação de um espaço com letra $\mathrm{x}$.

Como aporte teórico para as análises foram consideradas as pesquisas de Fernando Becker (BECKER, 2012; 2009; 1993) e noções da epistemologia de Gaston Bachelard (1996; 1971).

\section{RESULTADOS E ANÁLISES}

As respostas dos estudantes são apresentadas no quadro 1:

QUADRO 1 - Porcentagem de respostas às questões e Ranking Médio (RM)

\begin{tabular}{|c|c|c|c|c|}
\hline $\begin{array}{c}\text { Totalmente } \\
\text { de acordo }\end{array}$ & Questão 1 & Questão 2 & Questão 3 & Questão 4 \\
\hline De acordo & $43,08 \%$ & $23,08 \%$ & $7,69 \%$ & $7,69 \%$ \\
\hline Neutro & $7,69 \%$ & $46,15 \%$ & $46,15 \%$ & $7,69 \%$ \\
\hline Em desacordo & $23,08 \%$ & $7,69 \%$ & $38,46 \%$ & $7,69 \%$ \\
\hline $\begin{array}{c}\text { Totalmente em } \\
\text { desacordo }\end{array}$ & $0,0 \%$ & $0,0 \%$ & $0,0 \%$ & $46,15 \%$ \\
\hline RM & $\mathbf{3 , 6 9}$ & $\mathbf{3 , 8 5}$ & $\mathbf{3 , 5 4}$ & $30,77 \%$ \\
\hline
\end{tabular}

Fonte: os autores 
A questão 1 mostra que 69,23\% - soma dos dois primeiros itens - dos alunos concordam que as escolas com bons laboratórios têm um ensino de melhor qualidade e que $23,08 \%$, ou seja, quase um quarto dos estudantes, 0 fazem de forma veemente (ver tabela em totalmente de acordo). O RM de 3,69 significa que o resultado é: $3,5 \leq \mathrm{RM} \leq 4,4$ (de acordo).

A questão 2 mostra que 69,23\% - soma dos dois primeiros itens concordam que físicos observam a natureza e, a partir de sua observação elaboram as teorias. O RM de 3,85 significa que o resultado é: $3,5 \leq R M \leq 4,4$ (de acordo).

A questão 3 mostra que 53,84\% - soma dos dois primeiros itens concordam que Experimentos comprovam teorias. O RM de 3,54 significa que o resultado é: $3,5 \leq R M \leq 4,4$ (de acordo).

A questão 4 mostra que 76,92\% (soma dos dois últimos itens) não concordam que o professor deve transmitir o conhecimento e o aluno deve aceitá-lo passivamente. O RM de 2,15 significa que o resultado é: 1,5 $\leq$ RM $\leq$ 2,4 (em desacordo).

Em princípio, os dados poderiam parecer contraditórios, inviabilizando alguma inferência. No entanto, ao mostrar certa confusão quanto à origem do conhecimento, os resultados concordam com as pesquisas de Becker. Para os estudantes que participaram da pesquisa, atividades experimentais podem comprovar teorias e também gerar novos conhecimentos, ou seja, afirmam perspectivas ora racionalistas ora empiristas, tal como Becker (2012, 2009, 1993) já o fizera. Na discussão pós-questionário efetuada com os alunos, essa atribuição às experiências pôde ser confirmada. Nesse sentido, para os alunos, mesmo que de forma não consciente, as atividades experimentais parecem ter dupla finalidade, tanto a de criar teorias como a de comprová-las, reforçando uma concepção antagônica entre empirismo e racionalismo.

Consequentemente, para a maioria, o laboratório didático faz com que necessariamente a aprendizagem das ciências seja mais eficiente (respostas à questão 4), afinal, pensa o estudante que a partir dele as teorias 
podem ser tanto elaboradas (respostas à questão 2) quanto comprovadas (respostas à questão 3). Nesse sentido, um dos alunos citou uma universidade privada de outro Estado do país, para dizer que o ensino é "bem melhor porque o laboratório é incrível".

As pesquisas de Becker (2012) mostram também que quando o professor é questionado sobre fatores que envolvem a didática, existe em sua resposta um toque de construtivismo, e certa negação de aspectos referentes a um ensino por transmissão. Esse dado também aparece em nossa pesquisa (resposta à questão 4). Contudo, apesar desse discurso sobre o ensinar e o aprender dos estudantes segundo nossa pesquisa, e dos professores segundo Becker (2012), outras concepções por eles expressadas modificam o que poderia ter sido uma tendência didático-pedagógica e epistemológica.

O que parece acontecer é uma confusão entre teorias e práticas que não se coadunam e que, além disso, ao serem consideradas radicalmente, levam a um equívoco conceitual: a de considerar que o sujeito que aprende o faz de forma passiva:

Como se vê, o apriorismo opõe-se ao empirismo. Mas o faz apenas neste ponto, porque também ele acaba propondo uma visão passiva de conhecimento, pois, de uma ou de outra maneira, suas condições prévias já estão todas determinadas, independentemente da atividade do indivíduo (BECKER, 2009, p.90).

Os dados dessa pesquisa parecem indicar como corretos os resultados apontados por Becker. Apesar de não concordar com a estratégia de ensino que se pauta na transmissão e recepção de conhecimento (respostas à questão 4), os estudantes que responderam ao questionário e participaram das discussões parecem ter a concepção de que o aluno deve ser passivo ao observar atentamente um fenômeno ou experimento, às vezes para, a partir dele, elaborar conceitos científicos (respostas à questão 2), às vezes para confirmar as teorias estudadas (respostas à questão 3), encontradas nos livros ou explicadas pelo professor. 
Para Becker (2012; 2009; 1993), essas concepções que podem levar a certas práticas didáticas de forma inconsciente, poderão ser modificadas quando as mesmas são postas para reflexão, na qual elas são analisadas de um ponto de vista crítico. Nesse ponto, amparando-nos em Bachelard (1996; 1971), argumentamos que as concepções dos professores, ou futuros professores, quando não problematizadas não são transformadas ou modificadas, pois não há catarse, permanecendo mesmo após as práticas e os estudos universitários. Como consequência, são levadas para sala de aula após a graduação, disseminando noções equivocadas sobre 0 conhecimento a ser ensinado.

Quando não problematizado, o conhecimento assim ensinado, permite entender que as teorias e os conceitos científicos são edificações de objetos que se encontram fora dos sujeitos, no caso, dos cientistas que os elaboraram. Portanto, o aluno deve apenas escutar e prestar muita atenção (deve ser passivo), pois o saber que deve aprender vem totalmente de fora de si mesmo, não sendo ele um construtor do conhecimento.

A falta de consciência disso leva a respostas contraditórias, como as encontradas em nossa pesquisa. Ou seja, ao mesmo tempo em que o aluno se manifesta contra a transmissão do conhecimento e contra um aluno passivo, se manifesta dizendo que este mesmo conhecimento é algo que está fora do sujeito, e que, portanto, ele deve apreendê-lo, pois não sabe nada a seu respeito.

Dessa forma, amparando-nos em Bachelard (1996; 1971), o primeiro passo para enfrentar esse obstáculo didático-epistemológico é fazer com que ele venha à consciência do indivíduo, levando-o à reflexão e permitindo uma mudança em suas concepções e práticas, portanto, permitindo uma mudança em suas perspectivas educacionais pela compreensão dos aspectos epistemológicos nelas envolvidos. 


\section{CONCLUSÕES}

Concluímos, por meio deste trabalho, que as reflexões epistemológicas devem estar presentes no curso da formação docente, como outros autores já têm defendido (AUTH, ANGOTTI, 2003; MUENCHEN, DELIZOICOV, 2012), por meio de outras referências teóricas que em muitos pontos se afinam com as nossas. Além disso, é necessário um trabalho que objetiva uma formação em que os aspectos de âmbito didático-pedagógico estejam claramente relacionados às concepções epistemológicas subjacentes, permitindo revisões críticas quanto aos elementos teóricos e práticos durante a formação dos professores de ciências e de matemática.

Embora neste trabalho, a ênfase epistemológica tratada foi limitada à Gênese do Conhecimento, outros elementos da epistemologia são tão fundamentais quanto esta, para compreensão do que vem a ser a ciência ou o conhecimento em seus aspectos mais amplos.

Libâneo (2010), argumentando a favor da inserção da epistemologia na didática afirma:

\footnotetext{
Para se sustentar a idéia de que toda didática supõe uma epistemologia, é preciso admitir que o núcleo do problema didático é o conhecimento, no qual estão implicadas questões lógicas e psicológicas. Isso significa reconhecer os vínculos da didática com uma filosofia, especialmente, com uma posição epistemológica, a despeito do acentuado papel na constituição dessa disciplina da psicologia da educação, da sociologia da educação, da teoria social do currículo e, recentemente, da linguística (LIBÂNEO, 2010, p.2).
}

Como perspectivas para trabalhos futuros, temos como hipótese a ideia de que as mudanças parecem não ocorrer na efetiva prática dos professores porque suas antigas concepções sobre as ciências e o ensino e aprendizagem não se mostram contraditórias em si mesmas, o que não os levam a reflexões críticas a esse respeito, fazendo com que se relativize as novas compreensões em detrimento das suas próprias.

De acordo com esta compreensão, e tendo como objetivo formar professores que compreendam não somente a ciência, mas os elementos 
relacionados com o fazer ciência, se faz necessário um trabalho de conscientização das noções epistemológicas e didático-pedagógicas dos estudantes, a fim de analisá-las criticamente e problematizá-las.

\section{USO DE EXPERIMENTOS EM UMA DIDÁTICA INOVADORA}

A compreensão epistemológica dos elementos presentes no ensino e aprendizagem permite problematizar a formação docente quando 0 professor se encontra em uma situação em que em sua estratégia de ensino, apesar de seu esforço e dedicação, os alunos não se mostram motivados ou sujeitos de aprendizagem. Nesse cenário, os sujeitos que participam passivamente de uma didática da ciência que se concretiza por meio de experimentos que visam aprendizagem por reprodução, são vítimas de um sistema limitado à aprendizagem de um fazer técnico, de uma prática que muitas vezes não é capaz de resolver outras questões cotidianas ou profissionais. Nesse sentido, a aprendizagem não é significativa (DARROZ, ROSA, GHIGGI, 2015) e possui como causa a falta de envolvimento entre sujeito e objeto, capaz de estabelecer relações expressivas entre aluno e conhecimento.

Pesquisas efetuadas no contexto real de sala de aula, comparando aprendizagem de alunos submetidos a estratégias tradicionais (grupos de controle) e outros submetidos a estratégias focadas em dinâmicas em que concepções prévias foram discutidas por meio de aulas experimentais, mostraram que estes últimos tiveram resultados mais satisfatórios do ponto de vista da aprendizagem (por exemplo, ALVES, 2006).

As aulas experimentais podem ser utilizadas, portanto, como estratégias de ensino tradicionais e, de forma distinta, como caminhos para construção de conhecimentos capazes de proporcionar efetiva aprendizagem. Quando o aluno reflete e constrói seu próprio conhecimento, a perspectiva é de que uma aprendizagem duradoura (JONNAERT, 1996) possa ser constituída. Afinal, como afirmam Reginaldo, Sheid e Güllich (2012, 
p.10), "reproduzir experimentos ou copiar práticas" não resolve os problemas do ensino de ciências. Há necessidade de "uma aproximação do mundo real (contexto, cotidiano e teoria), analisando os fenômenos, integrando e interagindo para produzir conceitos" (REGINALDO, SHEID, GÜLLICH, 2012, p.10, grifo nosso, em negrito).

Esses autores também enfatizam os experimentos como artifícios didáticos em que

A relação entre teoria e prática é uma via de mão-dupla, na qual se vai dos experimentos à teoria e das teorias aos experimentos, para contextualizar, investigando, questionando, retomando conhecimentos e também construindo conceitos (REGINALDO, SHEID, GÜLLICH, 2012, p.11).

Tal como Bachelard (1996) deixa evidenciar, a formação de professores deve ser feita em uma concepção epistemológica crítica inserida entre a realidade - representada neste caso pelos experimentos - e o pensamento - representado neste caso pelas teorias -, entre objetos e sujeitos do conhecimento. Para Bachelard, experimentos são interpretados pelos indivíduos de acordo com suas formações prévias, experiências primeiras que fundam imaginários de senso comum. Estes, por sua vez, podem ser buscados na história que envolve os elementos constitutivos das experiências. São, portanto, pensamentos historicamente superados.

Os pensamentos e reflexos do senso comum trazem marcas de representações sócio-científicas que foram relevantes para os cientistas de determinadas épocas, as quais hoje, após superadas, constituiem o que Bachelard (BACHELARD, 1978) denomina de perfil epistemológico (formas de pensar sobre determinado elemento caracterizado pelas suas diversas nuances presentes na história).

Sendo o perfil epistemológico uma série de saberes, de senso comum e científicos, que leva os indivíduos a interpretarem situações e experiências (cotidianas, didáticas), se faz necessária sua elucidação para que, a partir delas, se elabore estratégias de ensino que levam à aprendizagem significativa. 
Fundamentando-se em Bachelard (1996, 1978), a história da ciência seria o caminho mais razoável para construção do novo conhecimento visando problematizar o senso comum dos indivíduos. Há uma quantidade substancial de trabalhos, pautados na epistemologia de Bachelard, tanto para sugerir olhares ou estratégias para o ensino de ciências (por exemplo, YAMAZAKI, 2010; MARTINS, 2006; MELO, 2005) como para fundamentação de pesquisas em Educação Científica (por exemplo, CEZARE, 2016; LABATI-TERRA et al., 2014; SOUZA, 2014; HONORATO, MION, 2009). Nesse contexto, é possível inserir as experiências relevantes encontradas na evolução dos conceitos que, muitas vezes, levaram a discussões analíticas internas à própria lógica ciência, mas também a controvérsias científicas (COLLINS, PINCH, 2010), enriquecendo e sofisticando os olhares formativos dos futuros professores.

\section{NOVOS RUMOS PARA DIDÁTICA DA FÍSICA}

Franklin, Sayre e Clark (2014) mostraram, por meio de uma pesquisa empírica, que alunos submetidos a uma estratégia de ensino tradicional tiveram aprendizagem de curto prazo, enquanto aqueles submetidos a uma estratégia de ensino na qual atuavam ativamente na construção do conhecimento, tiveram aprendizagem de longo prazo. Os autores mostraram que estes últimos levavam o conhecimento incorporado (sobre potencial elétrico) para as semanas seguintes, enquanto os primeiros perdiam a essência do mesmo. Em nossa opinião, trabalhos como esses, problematizam métodos de ensino transmissivistas que há décadas vem sendo questionados pela comunidade de pesquisadores da área de Educação. Embora pareça redundante, vale chamar a atenção para este ponto, porque ainda hoje pesquisas em distintas regiões mostram que professores se guiam e pensam conforme os parâmetros tradicionais de ensino (por exemplo, DARROZ, ROSA, GHIGGI, 2015; PAZ, 2014; REZENDE, OSTERMANN, 2005).

Essa verificação não nos surpreende, uma vez que outras pesquisas mostram correlações entre vivências dos indivíduos enquanto alunos, desde 
a Educação Básica, e suas práticas docentes futuras. Elas revelam concepções e práticas de vieses tradicionais vivenciadas nas escolas (QUADROS et al., 2005), dificultando a formação docente universitária mesmo que esta tenha efetivamente discussões e estudos no âmbito didático-pedagógico (QUADROS et al., 2010).

Essse cenário é complexificado na medida em que os próprios docentes de ensino universitário, que formam novos professores, não se adequam às atuais demandas educacionais, no âmbito didáticopedagógico, resistindo a inovações para sala de aula. Essa atitude revela uma compreensão epistemológica enraizada sobre ensino e aprendizagem que foi incorporada durante muitos anos escolares e universitários (SILVA, CARVALHO, 2009).

Como Becker (2009; 1993) e Bachelard $(1996,1978)$, aos quais fizemos referência - com os quais nossos resultados são congruentes - têm mostrado no decorrer das últimas décadas, os professores ou futuros professores não concebem o ensino como uma relação mútua entre sujeito e objeto, prevalecendo, do ponto de vista epistemológico, tendências empiristas ou aprioristas em suas práticas de sala de aula. Essa tendência a práticas específicas pode fazer com que as aulas, inclusive as experimentais, sejam ações transmissivistas, convencionais, que não têm a preocupação de discutir e problematizar concepções prévias que os alunos trazem como conteúdos incorporados pela vida.

Contudo, se fazem necessárias para avanços neste campo, o didático-pedagógico, formações acadêmicas nada triviais. Nós, professores das universidades de cursos de licenciaturas, estamos formando mal os professores ao não instrumentalizá-los para que possam proporcionar mudanças didáticas significativas, avanços que poderiam estar ocorrendo em função das pesquisas da área da educação científica. Não é incomum ouvir nos corredores ou nas reuniões de departamento, de colegiado ou mesmo pedagógicas, que precisamos investir em aulas experimentais, "mesmo que estas sejam convencionais". 
Esta perspectiva de planejamento e atuação não favorece avanços reais, pois ela carrega o reforço de toda a vivência escolar tradicional que cada um de nós traz para sala de aula, sob influência primeira da Educação Básica. Afinal, "o professor formador desempenha papel exemplar para a atuação docente, tanto ao adotar práticas consistentes com os resultados de pesquisa como ao manter práticas tradicionais de ensino" (DELIZOICOV, 2004, p.153).

Portanto, se as práticas que de fato são encontradas na formação inicial de professores, ou seja, nos cursos de licenciatura, especialmente para a docência em Física, apresentam-se conforme os modelos de ensino convencionais, como é possível formar novos professores com outras perspectivas didático-pedagógicas?

Resultados de pesquisas envolvendo investigadores que lidam com teorias fundadas em outros meios acadêmicos, como a sociologia, a filosofia e a psicologia buscam analisar esse cenário utilizando-se de noções que dizem respeito à reprodução de práticas irrefletidas durante a formação profissional e antes dela. Bourdieu (2010a; 2010b), por exemplo, através de conceitos cunhados por ele como habitus, procura mostrar como as práticas e pensamentos de um coletivo de indivíduos que compartilham de determinados valores e aprendizados, são reproduzidos e empregados de forma não consciente, pois se encontram naturalizados em seu meio.

Nesse contexto, Lenoir (2003) argumenta que essas práticas e apreensões estão fortemente relacionadas às instituições nas quais foram historicamente criadas, sendo, portanto, elementos a serem disseminados pelos próprios formadores. As tradições, dessa forma, não foram feitas para transformações e apresentam motivos para resistências. Sobre esse ponto, Lenoir (2003) afirma:

Pessoas que não têm a cultura requerida, carecendo tanto do conhecimento explícito quanto do conhecimento tácito a respeito do modo como funciona a instituição esborracham-se contra paredes de concreto: eles percebem a instituição como uma força que disciplina, oprimindo-as (no caso daqueles sobre os quais a 
disciplina é praticada de forma negativa ou daqueles que são sistematicamente excluídos do seu acessol ou gerando e organizando a competência (para aqueles que esperam se tornar iniciados na instituição) (LENOIR, 2003, p. 12).

Há criação de certa identidade vocacional, incorporada por coação disciplinar (FLECK, 2010), "estabelecendo problemas", "definindo ferramentas", organizando "esquemas de percepção, apreciação e ação", inculcando "ferramentas de cognição e comunicação" (LENOIR, 2003, p.65). Dessa forma,

É por meio da concepção da existência de uma internalização de padrões de discurso, de estruturas de conhecimento e de modos de prática que Lenoir (2003) apresenta a discussão em torno das disciplinas. Dessa forma, ele considera as disciplinas como "estruturas essenciais para sistematizar, organizar e incorporar as práticas sociais e institucionais das quais dependem tanto o discurso coerente quanto o exercício legítimo do poder" (p. 67).

Apesar da presença na formação profissional docente de elementos que tencionam em direção a certas práticas julgadas pela tradição de ensino de física como mais pertinentes à área, elas, tal como demonstram distintos autores (como Bourdieu, Fleck e Bachelard), são muitas vezes práticas impensadas, resultado de uma formação irrefletida, como já fizemos referência.

Nesse sentido, os campos acadêmicos integram linguagens, palavras, expressões próprias da área, que demonstram a inserção de cada novo membro e segundo as quais são avaliados (BECHER, 2001). Estes elementos, objetivos e subjetivos do campo, só podem ser apreendidos pela vivência, seja como aluno, seja como profissional, reforçando-as.

Segundo Milicic (2004), os egressos, durante sua vida profissional, são constantemente submetidos a avaliações a fim de se comprovar que os mesmos "cumprem os requisitos que são exigidos" para que continuem sendo considerados como legítimos membros de certa cultura acadêmica (MILICIC, 2004, p. 127).

As pesquisas de Becher (2001) e de Milicic (2004) "podem ser enquadradas como parte de uma tradição do campo da física, que pode ser encontrada em seus departamentos", "onde tal cultura é disseminada 
permitindo que outros indivíduos possam incorporá-la na forma de hábitos e pensamentos" (YAMAZAKI, 2015, p.40) que compõem a tradição de ensinar física.

Além disso,

Menezes e Vaz (2009) lembram que a Física, como parte do currículo da escola no Brasil preserva há muitas décadas características que hoje são conhecidas como parte de uma metodologia tradicional. Segundo esses autores, a crença na eficácia da educação tradicional no ensino de Física o tem tornado cada vez mais empobrecido, acarretando falta de interesse pela aprendizagem de Física, por parte dos alunos, que de certo, nem sabem o que, de fato, é Física e para que ela serve (YAMAZAKI, 2015, p.40).

Enfim, estamos apontando o quão difícil é modificar uma cultura acadêmica, principalmente quando seus membros não a vêem problematizadas. Refletindo sobre nosso objeto de estudo, os experimentos didáticos, inferimos que os alunos concebem experimentos como estratégias didáticas essenciais para que o ensino seja mais eficiente. Contudo, os dados parecem mostrar que os alunos investigados declinam às vezes para uma compreensão empirista, às vezes para uma compreensão apriorista ou racionalista no que tange ao papel das experimentações. Essas concepções sobre experimentos didáticos são resultantes de práticas vivenciadas, como é possivel sustentar pelas investigações supracitadas. Uma compreensão que, quando somadas a outras já superadas pela área, se constitui hoje como obstáculo complexo, difícil de ser levado a cabo, principalmente porque muitos dos membros que compõem os cursos de licenciaturas não os percebem como tais. Em outros termos, para eles, a didática não é um problema, ou no mínimo, um problema que vale a pena ser enfrentado.

Tendo em vista esta configuração, que se refere aos membros de cursos de formação inicial de professores de física, em nossa opinião, avanços só poderiam ocorrer se os resultados das pesquisas da área, referente ao tema, forem divulgados e discutidos não somente nos eventos para especialistas, mas para todos os docentes que trabalham ou que pretendem trabalhar nas licenciaturas. Seria uma forma de colocar a 
questão como atitude fundamental, se queremos avançar com a formação de professores. No entanto, pouco adiantaria se os professores não forem sensibilizados para a necessidade de refletir sobre o tema (YAMAZAKI, YAMAZAKI, 2013). A nós, tal reflexão-ação seria a tradução de catarse intelectual e afetiva que Bachelard insiste em propagar em suas obras. Ela poderia levar a transformações expressivas nas práticas dos professores, podendo proporcionar ao longo dos anos melhorias significativas na formação inicial de professores.

Afinal, pesquisas têm demonstrado que os aspectos relacionados às afetividades podem ser aliados ou fortes parâmetros para aceituação ou rejeição de novos saberes e práticas (por exemplo, CUSTÓDIO, 2007; PINHEIRO, 2003). Ainda neste campo, outras pesquisas mostram que os mecanismos psíquicos afetivo-cognitivos são muitas vezes inconscientes, e só podem ser conhecidos quando utilizamos conhecimentos de outras áreas científicas. Uma das alternativas refere-se aos investimentos no campo da psicanálise que desde a década de 1990 buscam, no Brasil, compreender os processos que guiam tanto estudantes como professores em eventos e fenômenos de sala de aula. Há atualmente, um acervo significativo de trabalhos com este enfoque, de artigos a teses de doutoramento (ARRUDA, 2001; BAROLLI, 1998; BARROS, 2002; ORQUIZA, 1994) - as pesquisas com este enfoque que foram desenvolvidas por este grupo são contextualizadas em VILLANI et al., 2006. Os autores apresentam projetos de ensino que foram satisfatórios e outros problemáticos, mostrando o potencial interpretivo da psicanálise (VILLANI, SANTANA, ARRUDA, 2003; BARROS, VILLANI, 2004). Ainda hoje, pesquisas são feitas nesta linha de investigação em algumas universidades brasileiras, indicando que os resultados apresentam motivos razoáveis para a continuidade dos investimentos intelectuais.

Por fim, pensamos que este é o caminho para enculturação de uma epistemologia crítica, pois seria possível uma sensibilização para mudanças. Enquanto não temos esses investimentos em escalas maiores que as pontuais pesquisas publicadas, continuamos com a conhecida epistemologia do 
senso comum. Segundo Becker (apud PÁTARO, 2012, p.13), a "epistemologia de senso comum pode barrar o desenvolvimento, tornando-o medíocre, enquanto uma epistemologia crítica abre caminhos para a novidade, a criatividade ou a inventividade".

\section{REFERÊNCIAS}

ALVES, V. de F. A inserção de atividades experimentais no ensino de Física em nível médio: em busca de melhores resultados de aprendizagem. 2006. 133f. Dissertação (Mestrado em Ensino de Ciências) - Universidade de Brasília, Brasília/DF, 2006.

ALVES, V. C.; STACHAK, M. A importância de aulas experimentais no processo ensino-aprendizagem em Física: "eletricidade". In: XVI Simpósio Nacional de Ensino de Física, 2005, Rio de Janeiro. Anais. Rio de Janeiro: Universidade Federal do Rio de Janeiro, 2005, de 24 a 28 de janeiro 2005. p.1-4.

ARRUDA, S. M. Entre a inércia e a busca: reflexões sobre a formação em serviço de professores de física do ensino médio. 2001. 238 f. Tese (Doutorado em Educação) - Universidade de São Paulo, São Paulo/SP, 2001.

AUTH, M. A.; ANGOTTI, J. A. P. Contribuições epistemológicas para o ensino/aprendizagem de Ciências. Contexto e Educação, v.18, n.69, 2003.

BACHELARD, G. A Formação do Espírito Científico. Rio de Janeiro: Contraponto, 1996.

BACHELARD, G. A Filosofia do Não: Filosofia do Novo Espírito Científico. São Paulo: Abril Cultural, 1978.

BACHELARD, G. A Epistemologia. Lisboa: Edições 70, 1971.

BARBOSA, J. de O.; PAULO, S. R. de; RINALDI, C. Investigação do papel da experimentação na construção de conceitos em eletricidade no ensino médio. Caderno Catarinense de Ensino de Física, v.16, n.1, p.105-122, 1999.

BAROLLI, E. Reflexões sobre o trabalho dos estudantes no laboratório didático. 1998. 193f. Tese (Doutorado em Educação) - Universidade de São Paulo, São Paulo/SP, 1998

BARROS, M. A. Análise de uma experiência didática com grupos de aprendizagem em Física. 2002. 107f. Tese (Doutorado em Educação) Universidade de São Paulo, São Paulo/SP, 2002.

BARROS, M. A.; VILLANI, A. A dinâmica de grupos de aprendizagem de física no ensino médio: um enfoque psicanalítico. Investigações em Ensino de Ciências, v.9, n.2, p.115-136, 2004.

BECHER, Tony. Tribus y territorios acadêmicos: la indagación intelectual y las culturas de las disciplinas. Barcelona/Espanha: Editora Gedisa, 2001. 256p. 
BECKER, F. Epistemologia do Professor de Matemática. Petrópolis, RJ: Vozes, 2012.

BECKER, F. 0 que é construtivismo? In: http://www.crmariocovas.sp.gov.br/pdf/ideias_20_p087-093_c.pdf. 2015. Acessado em 20/12/2015. Publicado em 2009.

BECKER, F. Epistemologia do Professor: o cotidiano da escola. Petrópolis, RJ: Vozes, 1993.

BOURDIEU, P. O Poder Simbólico. $13^{a}$ ed. Rio de Janeiro: Bertrand Brasil, $2010 a$. $314 \mathrm{P}$.

BOURDIEU, P. Escritos de Educação. $11^{a}$ edição. Petrópolis, RJ: Vozes, $2010 \mathrm{~b}$. $251 \mathrm{p}$.

CEZARE, P. S. L.; ANDRADE, M. A. B. S. de. A Epistemologia de Bachelard e a construção do conceito de adaptação das espécies. Investigações em Ensino de Ciências, v.21, n.3, p.53-73, 2016.

COLLINS, H.; PINCH, T. O Golem: o que você deveria saber sobre ciência. $2^{a}$ Edição. Belo Horizonte: Fabrefactum Editora, 2010. 257p.

CUSTÓDIO FILHO, J. F. Explicando explicações na educação científica: domínio cognitivo, status afetivo e sentimento de entendimento. 2007. $236 \mathrm{f}$. Tese (Doutorado em Educação Científica e Tecnológica) - Universidade Federal de Santa Catarina, Florianópolis/SC, 2007.

BONADIMAN, H.; NONENMACHER, S. E. B. O gostar e o aprender no ensino de Física: uma proposta metodológica. Caderno Brasileiro de Ensino de Física, v.24, n.2, p.194-223, 2007.

DARROZ, L. M.; ROSA, C. W. da; GHIGGI, C. M. Método Tradicional $x$ Aprendizagem Significativa: investigação na ação dos professores de Física.

Aprendizagem Significativa em Revista/Meaningful Learning Review, v.5, n.1, p. 70-85, 2015.

DELIZOICOV, D. Pesquisa em Ensino de Ciências como Ciências Humanas Aplicadas. Caderno Brasileiro de Ensino de Física, v.21, n.2, p. 145-75, 2004.

FLECK, L. Gênese e Desenvolvimento de um Fato Científico. Belo Horizonte/MG: Fabrefactum, 2010. 224p.

FRANKLIN, S. V.; SAYRE, E. C.; CLARK, J. W. Traditionally taught students learn; actively engaged students remember. American Journal of Physics, v.82, n.8, p.798-801, 2014.

GIORDAN, M. O papel da experimentação no ensino de ciências. In: ॥ Encontro Nacional de Pesquisa em Educação em Ciências - II ENPEC, 1999, Valinhos. Anais... Valinhos, SP, de 01 a 04 de setembro 1999. p.1-13. 
HESSEN, J. Teoria do Conhecimento. São Paulo: Martins Fontes, 2000.

HIGA, I.; OLIVEIRA, O. B. de. A experimentação nas pesquisas sobre o ensino de Física: fundamentos epistemológicos e pedagógicos. Educar em Revista, n.44, p.75-92, 2012.

HONORATO, M. A.; MION, R. A. A importância da problematização na construção e aquisição do conhecimento científico pelo sujeito. In: VII Encontro Nacional de Pesquisa em Educação em Ciências, 2009, Florianópolis. Anais. Florianópolis: Universidade Federal de Santa Catarina, 2009, de 08 a 13 de novembro 2009. p.1-12.

JONNAERT, P. Dévolution versus contre-dévolution! Un Tandem Incontournable pour le contrat didactique. In: RAISKY, C.; CAILLOT, M. (Éds). Au-delà des didactiques: débats autour de concepts fédérateur. Belgium: De Boeck \& Larcier S.A., 1996. 278p. p.115-158.

JORDÃO, G. R.; BARRIO, J. B. M. Experimentação no ensino de Física: o plano inclinado numa perspectiva do laboratório divergente. In: X Encontro de Pesquisa em Educação em Ciências, 2015, Águas de Lindóia. Anais... Águas de Lindóia, SP, 24 a 27 de novembro 2015. p.1-8.

LABATI-TERRA, L. et al. Identificação de obstáculos epistemológicos em um artigo de divulgação científica - entraves na formação de professores de ciências? Revista Electrónica de Enseñanza de las Ciencias, v.13, n.3, p.318333, 2014.

LENOIR, T. Instituindo a Ciência: a produção cultural das disciplinas científicas. São Leopoldo, RS: Editora UNISINOS, 2003.

LIBÂNEO, J. C. A integração entre didática e epistemologia das disciplinas: uma via para a renovação dos conteúdos da didática. In: XV Encontro Nacional de Didática e Práticas de Ensino - ENDIPE, 2010. Belo Horizonte, MG, Anais. Belo Horizonte: Universidade Federal de Mingas Gerais (UFMG), 20 a 23 de abril 2010. p.1-12.

LIKERT, R. A Technique for the measurement of attitudes. Archives of Psychology, v.22, n.140, 1932.

MARTINS, A. F. P. Algumas contribuições da epistemologia de Gaston Bachelard a pesquisa em ensino de ciências. In: X Encontro de Pesquisa em Ensino de Física, 2006, Londrina. Anais... Londrina, PR, 15 a 19 de agosto 2006. p.1-11.

MELO, A. C. S. de. Contribuições da epistemologia histórica de Bachelard no estudo da evolução dos conceitos da óptica. 2005. 198f. Dissertação (Mestrado em Educação Científica e Tecnológica) - Universidade Federal de Santa Catarina, Florianópolis/SC, 2005.

MILICIC, B. La cultura profesional como condicionante de la adaptación de los profesores de Física universitaria a la enseñanza de Física. 2004. 1700f. Tese 
(Doutorado - Faculta de Filosofía y Ciencias de la Educación) - Universitat de Valencia, Valencia/Espanha, 2004.

MUENCHEN, C.; DELIZOICOV, D. A construção de um processo didáticopedagógico dialógico: aspectos epistemológicos. Revista Ensaio, v.14, n.3, p.199-215, 2012.

MORAES, J. U. P.; SILVA JUNIOR, R. S. Experimentos didáticos no ensino de Física com foco na aprendizagem significativa. Aprendizagem Significativa em Revista, v.4, n.3, p.61-67, 2014.

ORQUIZA DE CARVALHO, L. Representações mentais e conflitos cognitivos: o caso das colisões em Mecânica. 1994. 342 f. Tese (Doutorado em Educação) - Universidade de São Paulo, São Paulo/SP, 1994.

PÁTARO, R. F. Discussões sobre a epistemologia do trabalho docente Fernando Becker. Revista Educação e Linguagens, v.1, n.1, p.9-22, 2012.

PAZ, F. S. A Prática Docente do Professor de Física: percepções do formador sobre o ensino. 2014. 130f. Dissertação (Mestrado em Educação) Universidade Federal do Piaú, Teresina/PI, 2014.

PENA, F. L. A.; RIBEIRO FILHO, A. Obstáculos para o uso da experimentação no ensino de física: um estudo a partir de relatos de experiências pedagógicas brasileiras publicados em periódicos nacionais da área (19712006). Revista Brasileira de Pesquisa em Educação em Ciências, v.9, n.1, p.113, 2009.

PINHEIRO, T. F. Sentimento de realidade, afetividade e cognição no ensino de Ciências. 2003. 245f. Tese (Doutorado em Educação) - Universidade Federal de Santa Catarina, Florianópolis/SC, 2003.

PINHO ALVES FILHO, J. de. Regras da transposição didática aplicadas ao laboratório didático. Caderno Catarinense de Ensino de Física, v.17, n.2, p.174-182, 2000.

QUADROS, A. L. de et al. As práticas educativas e seus personagens na visão de estudantes recém-ingressados nos cursos de Química e Biologia. Ciência \& Educação, v.16, n.2, p.293-308, 2010.

QUADROS, A. L. de et al. Os professores que tivemos e a formação da nossa identidade como docentes: um encontro com a nossa memória. Ensaio Pesquisa em Educação em Ciências, v.7, n.1, p.1-8, 2005.

REGINALDO, C. C.; SHEID, N. J.; GÜLLICH, R. I. da C. O Ensino de Ciências e a Experimentação. In: IX ANPED SUL, 2012, Caxias do SUl, RS. Anais... Caxias do Sul: Universidade de Caxias do Sul, de 29 de julho a 01 de agosto 2012.

REZENDE, F.; OSTERMANN, F. A prática do professor e a pesquisa em ensino de física: novos elementos para repensar essa relação. Caderno Brasileiro de Ensino de Física, v.22, n.3, p.316-337, 2005. 
SILVA, L. F.; CARVALHO, L. M. de. Professores de Física em formação inicial: o ensino de física, a abordagem CTS e os temas controversos. Investigações em Ensino de Ciências, v.14, n.1, p.135-148, 2009.

SOUZA, P. H. Epistemologia e Cultura no Ensino de Física: desvelando os conceitos de tempo e espaço. 2015. 377f. Tese (Doutorado em Ensino de Ciências) - Universidade de São Paulo, São Paulo/SP, 2014.

VILLANI, A. et al. Contribuições da Psicanálise para uma metodologia de pesquisa em educação em ciências. In: SANTOS, Flavia M. T.; GRECA, lleana M. (Eds.). A Pesquisa em Ensino de Ciências no Brasil e suas Metodologias. ljuí, RS: Editora Unijuí, 2006. p. 323-390.

VILLANI, A.; SANTANA, D. de A.; ARRUDA, S. M. Perfil Subjetivo: estudos de caso. Caderno Brasileiro de Ensino de Física, v.20, n.3, p.336-371, 2003.

YAMAZAKI, S. C. Tradição do Ensino de Física em Manuais de Ensino Superior. 2015. 280f. Tese (Doutorado em Educação Científica e Tecnológica) Universidade Federal de Santa Catarina, Florianópolis/SC, 2015.

YAMAZAKI, S. C. As resistências para compreensão da teoria da relatividade especial. 1998. 126f. Dissertação (Mestrado em Ensino de Ciências modalidade física) - Universidade de São Paulo, São Paulo/SP, 1998.

YAMAZAKI, S. C.; YAMAZAKI, R. M. O. O lugar da subjetividade na educação científica: uma nova racionalidade para as mudanças conceituais. Revista Metáfora Educacional, v.14, p.29-49, 2013.

YAMAZAKI, R. M. O. Construção do Conceito de Gene por meio de jogos pedagógicos. 2010. 171f. Dissertação (Mestrado em Ensino de Ciências) Universidade Federal de Mato Grosso do Sul, Campo Grande/MS, 2010.

Recebido em: Fevereiro de 2017

Aceito em: Junho de 2017 